\title{
Editorial: III Encuentro de Editores de Revistas Científicas
}

La Revista Venezolana de Gerencia (RVG) nació en 1996 para ser editada semestralmente, periodicidad que se cumplió hasta 1998. En 1999 se inicia su publicación cuatrimestral y asi fue editada por dos años. Con el número 13 iniciamos la edición trimestral, intentamos asi dar mayor respuesta a la numerosa demanda de artículos que cumplen los requisitos de calidad, tan necesarios en momentos en los cuales el desarrollo cientifico y particularmente en materia gerencial, constituye un requerimiento para la transformación en nuestros paises.

Preocupados por el quehacer editorial para el mejoramiento permanente de la RVG, asistimos recientemente al III Encuentro de Editores de Revistas Científicas, realizado en La Habana, Cuba, organizado por el Instituto de Ciencia Animal perteneciente al Ministerio de Educación Superior de la República de Cuba, al cual queremos dedicar el editorial de este número. Fue un compromiso que surgió espontáneamente de quienes participamos como editores de Revistas, dedicar un espacio a reseñar tan importante evento para el aprendizaje y ef avance en la definición de criterios en una materia tan significativa hoy en día para la ciencia como lo es su difusión.

El Encuentro contó con la participación de 58 delegados nacionales y 19 extranjeros, relacionados con el quehacer editorial en todos sus aspectos. Los participantes representaban a 26 instituciones cubanas y 15 extranjeras de Argentina, Chile, Colombia, Costa Rica, Honduras, México, Panamá y Venezuela. En un grato ambiente profesional y social se compartió durante tres días sobre diversos temas de interés para editores y profesionales relacionados con el trabajo editorial.

El III Encuentro ha dado continuidad a los temas abordados en los dos primeros, efectuados en 1996 y 1998, en el mismo lugar del Instituto de Ciencia Animal. Los temas fundamentales que planificó la organización y en tomo al cual se discutió y reflexionó durante las reuniones, estuvieron relacionados con los sistemas de edición, arbitraje y publicación de articulos cientificos, indicadores de calidad, impacto económico y social de las revistas científicas, posibilidades de integración, las publicaciones electrónicas, y vias para la divulgación y comercialización de las revistas científicas. Se presentaron dos Conferencias Plenarias, dictadas por invitados de Chile y de México, una Mesa Redonda sobre la escritura, arbitraje, edición y traducción de articulos científicos, con tres panelistas cubanos y discusión por parte de los participantes. Hubo también 30 ponencias en los más variados temas de interés en el trabajo editorial y una sección de intercambio de experiencias. La masiva participación en todas las sesiones programadas y la calidad de los trabajos presentados, evidenciaron el alto interés porlos temas 
abordados. A esto se debe agregar el grato ambiente de trabajo, la buena organización, las atenciones de los anfitriones y del equipo local, que hicieron que el trabajo realizado fuera eficiente y cumpliera con éxito los planes trazados en su organización.

Entre las conclusiones más importantes que se derivan de las discusiones y opiniones planteadas por los conferencistas, expositores y participantes en general, destacan: i) el trabajo editorial se ve dificultado por varios factores ajenos al control del Editor, práctica que debe ser mejorada en el futuro; ii) las revistas apoyadas por universidades, por centros de investigación, o por organizaciones profesionales deben constituir un compromiso institucional para asegurar su permanencia y proyección en el tiempo; iii) el logro de mejores índices de calidad en las publicaciones debe ser un tarea prioritaria de los Editores en los próximos años; iii) es necesario velar por el cumplimiento de normas éticas elementales y denunciar a la comunidad editorial sobre acciones indebidas de parte de los autores, cuando estas ocurran y estén plenamente demostradas; iv); se requiere trabajar en la ubicación de revistas en Internet y aumentar las publicaciones electrónicas.

Importante fue también la discusión sobre la visibilidad, la comercialización y los retos para la continuidad de las revistas de Latinoamérica, asi como las experiencias de las editoriales. Se deberá formalizar vínculos que permitan una mayor colaboración y un mejor intercambio para propiciar soluciones a los problemas comunes.

En el ámbito de proyectos futuros y concretos se trabajará en la formación de un buzón electrónico en forma de una sociedad virtual, en la mayor intemacionalización del Encuentro, sobre lo cual está trabajando activamente el Dr. José Valderrama, de Chile, y en algunos cambios en las modalidades de presentación para el próximo Encuentro, si éste se hace más masi. vo, como esperamos. La necesidad de que estos Encuentros se sigan celebrando, fue una opinión unánime de todos los participantes, acordándose la realización del IV Encuentro para Noviembre del año 2002.

Invitamos a los editores de revistas científicas a estar atentos a tan importante evento, la comunicación entre editores latinoamericanos constituye hoy en día una necesidad para avanzar en la conformación de criterios que nos permitan avanzar en el reconocimiento de nuestras publicaciones de calidad, relegadas hasta ahora.

* Directora de la Revista Venezolana de Gerencia. 